\title{
Sosialisasi dan Edukasi SNI 2052:2017 Tentang Baja Tulangan Beton Di SMKN 4 Tangerang
}

\author{
Devita Mayasari ${ }^{1}$; Budi Wicaksono ${ }^{2}$; Tommy Iduwin ${ }^{3}$; \\ Pratiwi Setyaning Putri ${ }^{4}$; Tri Yuhanah \\ 1,2,3,4,5Sekolah Tinggi Teknik PLN \\ Program Studi Teknik Sipil \\ 11devita@sttpln.ac.id
}

\begin{abstract}
Concrete reinforced steel is an important material in reinforced concrete construction. The ability of concrete reinforcement in accepting high tensile strength and weakness of concrete in tensile strength are basic of reinforced concrete. Each country has its own standards, including Indonesia which has the Indonesian National Standard (SNI). SNI is often updated to keep abreast of the latest developments in science and knowledge. At present the latest standard used for concrete reinforcing steel in Indonesia is SNI 2502: 2017. However, this standard has not been well socialized due to limited costs and resources. With the Community Partnership Program activities's theme "Dissemination and Education of SNI 2052: 2017 Concerning Concrete Reinforcing Steel in SMKN 4 Tangerang" able to provide knowledge and understanding to teachers and students of SMKN 4 Tangerang, especially at Stone and Concrete Construction Engineering of Civil Engineering.
\end{abstract}

Keywords: concrete reinforced steel, concrete construction, SNI 2052:2017

\begin{abstract}
ABSTRAK
Material baja tulangan beton beton merupakan material yang penting dalam konstruksi beton bertulang. Kemampuan tulangan beton dalam menerima kuat tarik yang tinggi dan kelemahan beton dalam kuat tarik menjadi dasar pembuatan beton bertulang. Setiap negara memiliki standar masingmasing, tak terkecuali Indonesia yang memiliki Standar Nasional Indonesia (SNI). SNI seringkali dilakukan update dalam mengikuti perkembangan ilmu dan pengetahuan terbaru. Pada saat ini standar yang digunakan untuk baja tulangan beton di Indonesia yang terbaru adalah SNI 2502:2017. Namun standar ini belum tersosialisasikan dengan baik karena keterbatasan biaya dan sumber daya. Dengan adanya kegiatan Program Kemitraan Masyarakat dengan tema "Sosialisasi dan Edukasi SNI 2052:2017 Tentang Baja Tulangan Beton Di SMKN 4 Tangerang” mampu memberikan pengetahuan dan pemahaman kepada para guru dan siswa SMKN 4 Tangerang khususnya Jurusan Teknik Sipil Teknik Konstruksi Batu dan Beton.
\end{abstract}

Kata kunci: baja tulangan beton, konstruksi beton, SNI 2052:2017 


\section{PENDAHULUAN}

\subsection{Analisis Situasi}

SNI adalah standar yang ditetapkan oleh Badan Standardisasi Nasional (BSN) dan berlaku secara nasional diIndonesia ${ }^{[1]}$. Mengacu pada International Organization for Standardization (ISO), tujuan ditetapkannya standar diantaranya ${ }^{[1]}$ :

a. Menjaga keamanan, keselamatan dan kesehatan

Standardisasi produk untuk menjamin keamanan, keselamatan dan kesehatan bagi pemakainya

b. Menjamin kepentingan konsumen dan masyarakat

Kepentingan konsumen tidak hanya terbatas pada aspek keamanan, keselamatan dan kesehatan, tetapi juga kinerja produk. Konsumen selalu mengharapkan produk yang dibeli bekerja dengan baik, sesuai dengan fungsi yang diharapkan atau jumlah yang dibayarkan.

Menurut SNI 2052:2017 tentang baja tulangan beton, baja tulangan merupakan baja yang digunakan untuk penulangan dalam konstruksi beton bertulang yang berfungsi untuk menahan gaya tarik yang bekerja pada berbagai konstruksi. Baja tulangan berupa baja karbon atau baja panduan yang berbentuk batang berpenampang bundar dengan permukaan polos atau ulir dan diproduksi denga cara hot rolling ${ }^{[2]}$. Baja tulangan diproses melalui beberapa tahapan, diantaranya ${ }^{[2]}$ :

1. Dimulai dari bijih besi (ore) yang berada di alam. Kemudian biji besi ditambang dan diangkut menggunakan alat berat.

2. Proses Penghancuran (Crushing).

Bahan baku dalam bentuk batuan atau pasir dihancurkan sampai ukuran menjadi mesh 10. Dimaksudkan untuk memperbesar luas permukaan dari material sehingga memudahkan untuk proses selanjutnya

3. Proses Penghalusan (Grinding)

Dimaksudkan agar butiran halus bijih besi lebih banyak lagi terpisah dengan kotoran atau mineral mineral ikutan yang tidak diinginkan, proses ini sampai menhasilkan ukuran 120 mesh

4. Proses Pemisahan (Magnetic Separator)

Untuk memisahkan material logam dan non logam dengan pencucian dengan menggunakan air dalam mesin silender yang dilapisi magnet apabila bijih besi tersebut banyak mengandung hematit $\mathrm{Fe} 2 \mathrm{O} 3$ atau magnetit ( $\mathrm{Fe} 3 \mathrm{O} 4)$ akan terpisah sempurna sehingga kemurnian dari oksida besi meningkat

5. Proses Pemanggangan (Roasting)

Proses ini dilakukan material bijih besi banyak mengandung bijih hematit $\left(\mathrm{Fe}_{2} \mathrm{O}_{3}\right)$ diubah menjadi magnetit $\left(\mathrm{Fe}_{3} \mathrm{O}_{4}\right)$ yang mempunyai daya magnit lebih kuat sehingga terpisah antara material yang non magnet dan dihasilkan kadar Fe sampai $65 \%$ 


\section{Proses Pembuatan Pellet (Pan Palletizer)}

Sebelum masuk ke alat ini material bijih besi dicampur dalam alat mixer agitator dengan komposisi tertentu ditambahkan batubara dan binder bentonit dengan tujuan agar konsentrat besi oksida halus dapat merekat membentuk gumpalangumpalan (aglomerisasi yang disebut pellet basah (green pellet) yang mempunyai kekuatan yang cukup kuat untuk dapat dibawa ke proses selanjutnya, sedang batubara fungsinya untuk meningkatkan kadar besi dengan cara proses reduksi dari internal pada proses selanjutnya

7. Produksi Pig Iron

Hasil pellet (green pellet) yang dihasilkan dari proses pelletizer dimasukkan dalam tungku (blast furnace) dimasukkan larutan kapur, gas CO sebagai zat pereduksi dengan temperatur tertentu, kemudian akan mengalami proses pelelehan (melting) sehingga terpisah antara kandungan yang banyak mengandung logam besi $(\mathrm{Fe})$ dan akan terpisah karena perbedaan berat jenis dari kotorannya (slag), kemudian kandungan besinya akan masuk ke mesin casting (cetak) sesuai kebutuhan dengan kandungan Fe total 95\% dalam produk jadi Pig Iron

\section{Blust Furnace}

Dapur tinggi mempunyai bentuk dua buah kerucut yang berdiri satu di atas yang lain pada alasnya. Pada bagian atas adalah tungkunya yang melebar ke bawah, sehingga muatannya dengan mudah meluncur kebawah dan tidak terjadi kemacetan. Bagian bawah melebar ke atas dengan maksud agar muatannya tetap berada di bagian ini. Dapur tinggi dibuat dari susunan batu tahan api yang diberi selubung baja pelat untuk memperkokoh konstruksinya. Dapur diisi dari atas dengan alat pengisi. Berturut-turut dimasukkan kokas, bahan tambahan (batu kapur) dan bijih besi

9. Pencetakan ke dalam bentuk tulangan 


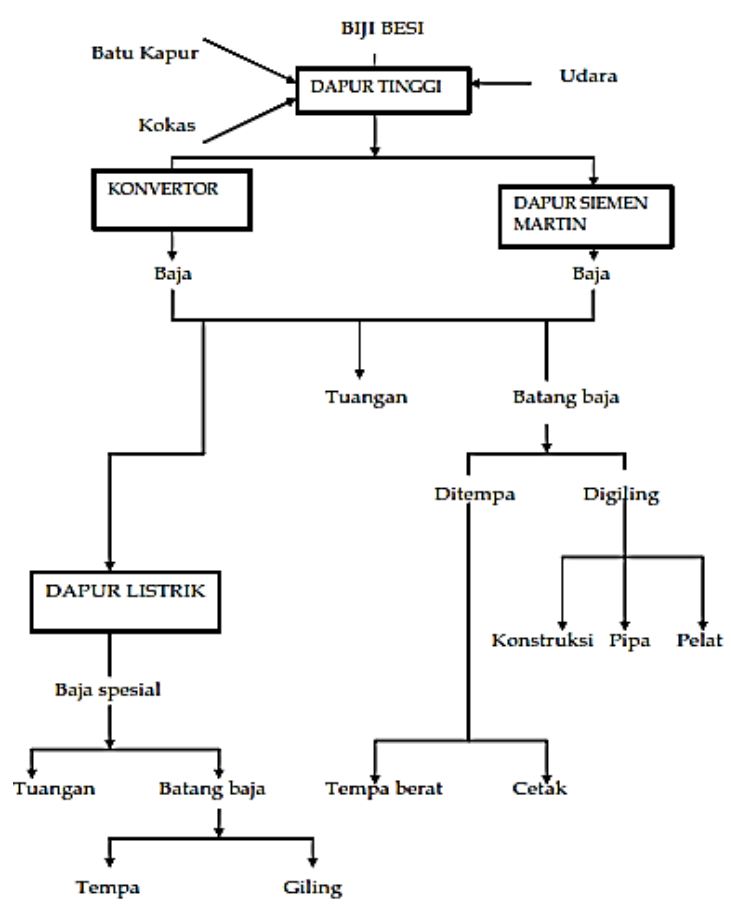

Gambar 1. Proses Pengolahan Baja

Jenis Baja tulangan terbagi menjadi menjadi baja tulangan beton polos dan baja tulangan beton sirip. Baja tulangan beton polos adalah baja tulangan beton berpenampang bundar dengan permukaan rata tidak bersirip disingkat, BjTP. Sedangkan baja tulangan beton bersirip adalah baja tulangan beton dengan bentuk khusus yang permukaannya memiliki sirip melintang dan memanjang yang dimaksudkan untuk meningkatkan daya lekat dan guna menahan gerakan membujur dari batang secara relative terhadap beton, disingkat BJTS $^{[3]}$.

SMKN 4 Tangerang yang terletak di Jl. Veteran No.1A, Babakan, Kota Tangerang, Banten merupakan sekolah yang memiliki Jurusan Teknik Sipil (Teknik Konstruksi Batu Dan Beton, Teknik Gambar Bangunan, Teknik Survey Dan Pemetaan Dan Teknik Kayu). Saat ini telah disahkan SNI terbaru tentang baja tulangan beton yakni SNI 2052:2017 dan setelah dikonsultasikan dengan pihak mitra diketahui bahwa aturan tersebut masih belum disosialisasikan. Melalui hasil PKM diharapkan sekolah-sekolah memahami dan mengerti tentang standar baja tulangan beton mulai dari proses pengolahan, jenis, persyaratan mutu, dan lain-lain.

\subsection{Permasalahan Mitra}

Mitra masyarakat yang akan bekerjasama melaksanakan Program Kemitraan Masyarakat (PKM) dengan tim pengusul adalah SMKN 4 Tangerang yang berlokasi di Jl. Veteran No.1A, Babakan, Kota Tangerang, Banten. Setelah dilakukan kunjungan ke lokasi Mitra diketahui bahwa pengetahuan para siswa dan guru tentang SNI 2052:2017 tentang baja tulangan beton masih minim. Hal ini perlu segera diatasi dengan diadakannya kegiatan sosialisasi dan edukasi kepada para siswa dan guru untuk meningkatkan pengetahuan 
mengenai SNI 20522017 tentang baja tulangan beton. Setelah diadakannya kegiatan PKM ini, diharapkan peserta kegiatan PKM dapat mengenal dan memahami:

a. Keberadaan standar yang dapat ditemui dalam kehidupan sehari-hari dalam hal ini SNI 2052:2017 tentang baja tulangan beton.

b. Fungsi dan manfaat dari standar SNI 2052:2017 tentang baja tulangan beton dalam kehidupan (memilih tulangan yang baik sebagai material konstruksi).

c. Alasan pentingnya dalam mengenal dan memahami standar SNI 2052:2017 tentang baja tulangan beton.

d. Kegunaan mengenal dan memahami standar SNI 2052:2017 tentang baja tulangan beton.

\section{METODE}

\subsection{Sifat dan Bentuk Kegiatan}

Kegiatan Program Kemitraan Masyarakat mengenai Sosialisasi dan edukasi SNI 2052:2017 tentang baja tulangan beton di SMKN 4 Tangerang dilakukan melalui beberapa tahapan, antara lain:

1. Pembentukan tim PKM yang terdiri dari 6 orang dosen STT-PLN Jakarta

2. Pencarian mitra dan identifikasi masalah mitra, yang menjadi mitra PKM adalah SMKN 4 Tangerang dan kemudian diketahui bahwa pengetahuan mitra akan SNI baja tulangan masih minim

3. Penyusunan program dan pembagian job desk setiap anggota tim supaya kegiatan berjalan dengan lancar

4. Pelaksanaan sosialisasi dan edukasi dilakukan dalam satu sesi dan diikuti oleh 3040 peserta. Kegiatan ini akan dilaksanakan dalam waktu satu hari kerja. Setiap peserta akan diberikan materi tentang standar baja tulangan beton yang laik digunakan pada konstruksi ${ }^{[1]}$. Pelaksanaan sosialisai dan edukasi ini dilakuka dengan beberapa langkah, yaitu:

a. Peserta melakukan pre test mengenai topik baja tulagan beton

b. Peserta sosialisasi dan edukasi diberikan teori dan pemahaman tentang SNI 2052;2017 serta upaya-upaya yang dilakukan pada saat memeriksa tulangan yang baik digunakan pada bangunan konstruksi.

c. Peserta diberikan kesempatan bertanya kepada presentator.

d. Peserta melakukan post test mengenai topik yang telah disampaikan.

5. Evaluasi dan penyusunan laporan kegiatan Program Kemitraan Masyarakat

\subsection{Diagram Alir Kegiatan}

Kegiatan Program Kemitraan Masyarakat mengenai Sosialisasi dan edukasi SNI 2052:2017 tentang baja tulangan beton di SMKN 4 Tangerang mengikuti acuan diagram alir berikut: 


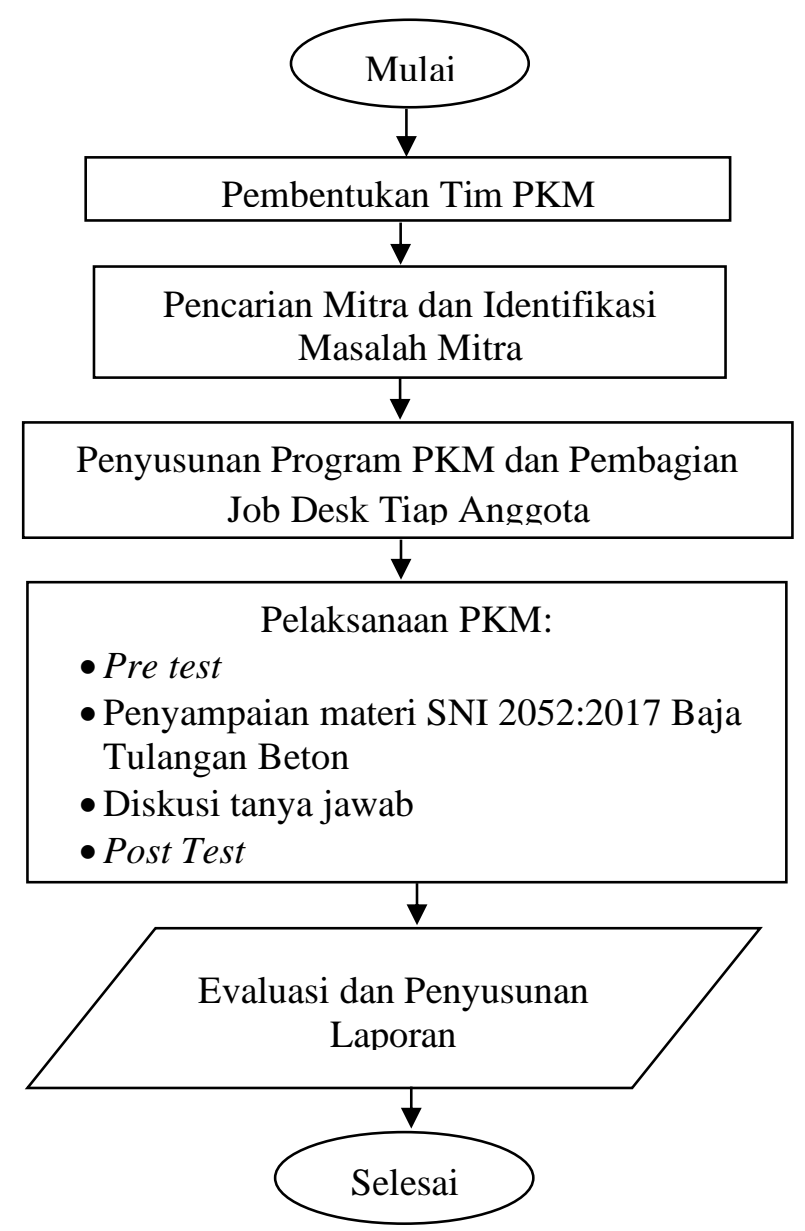

Gambar 2. Diagram Alir Kegiatan

\section{HASIL DAN PEMBAHASAN}

Kegiatan Program Kemitraan Masyarakat ini diawali dengan pembentukan tim dan survei pendahuluan di Bulan September 2018. Dari hasil survei tersebut, kemudian dilakukan analisis untuk menentukan kebutuhan mitra. Setelah kebutuhan mitra ditentukan, disusun skenario kegiatan serta dipersiapkan semua bahan dan perlengkapan yang akan digunakan untuk kegiatan sosialisasi dan edukasi.

Kegiatan sosialisasi dan edukasi dimulai dengan sambutan dari Kepala Sekolah SMKN 4 Tangerang dan Ketua Tim PKM STT-PLN. Selanjutnya siswa-siswi diberikan post test untuk mengetahui tingkat pengetahuan awal siswadan siswi mengenai baja tulangan beton. Siswa dan siswi SMKN 4 Tangerang belum memahami secara menyeluruh penerapan SNI berserta parameter baja tulangan beton berkaitan dengan keamanan konstruksi, keselamatan, dan kesehatan bagi pemakai serta menjamin kepentingan konsumen dan masyarakat ${ }^{[1]}$. Hal ini dilihat dari hasil pre test yang cukup rendah. Kegiatan selanjutnya 
adalah pemaparan materi tentang edukasi SNI 2052:2017 tentang baja tulangan beton ${ }^{[1]}$ yang disampaikan oleh Tim PKM STT-PLN dan dilanjutkan dengan diskusi tanya jawab.

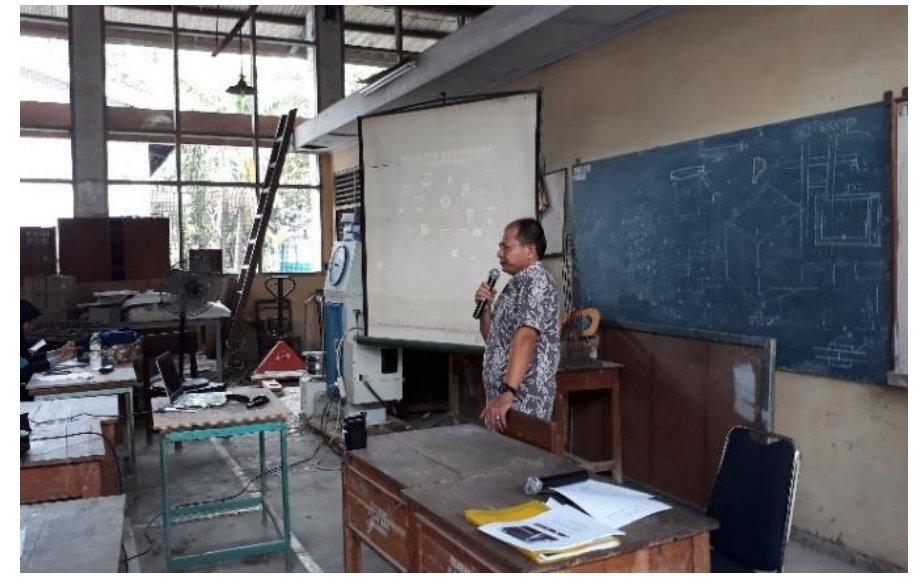

Gambar 3. Sambutan Mitra PKM

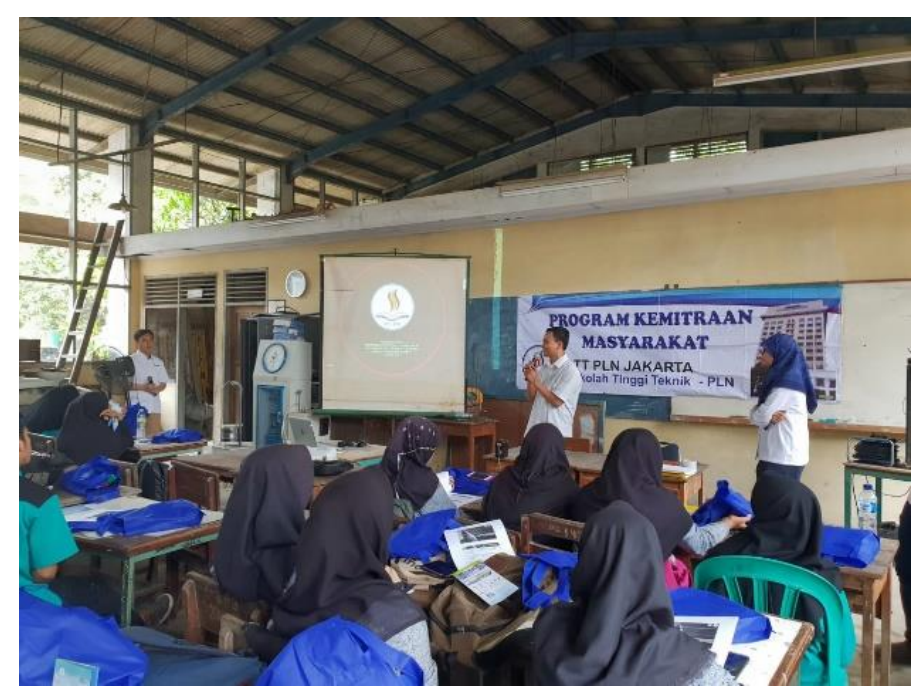

Gambar 4. Pemaparan Materi

Selama kegiatan berlangsung, terlihat antusias peserta yang cukup besar. Hal ini tampak dari semangat para peserta selama sesi pemaparan materi dan adanya timbal balik dari peserta pada sesi tanya jawab. Setelah penyampaian materi edukasi selesai dilakukan kembali kegiatan post tes yang dilakukan oleh siswa dan siswi SMKN 4 Tangerang. 


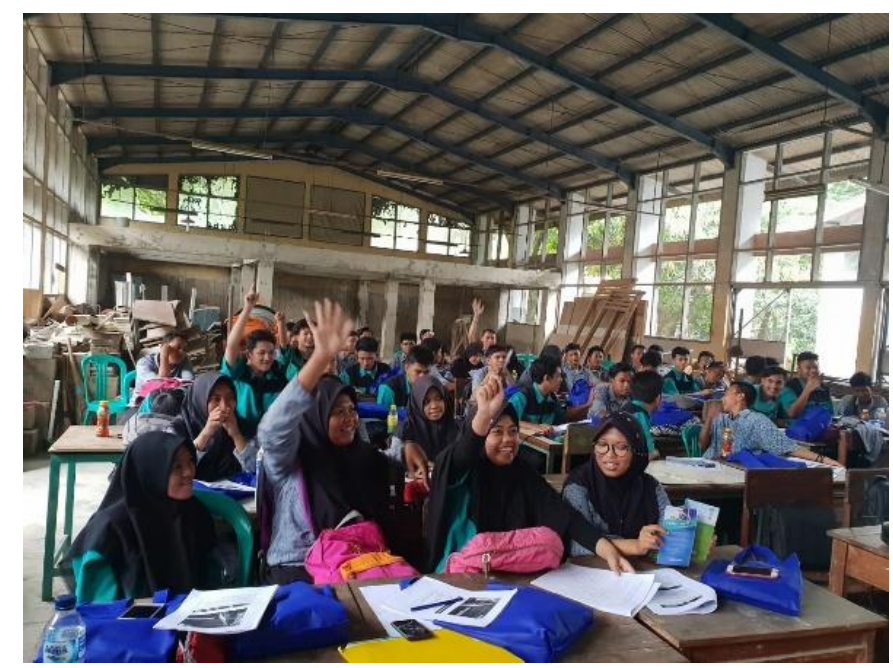

Gambar 5. Antusias Peserta Mengikuti Kegiatan

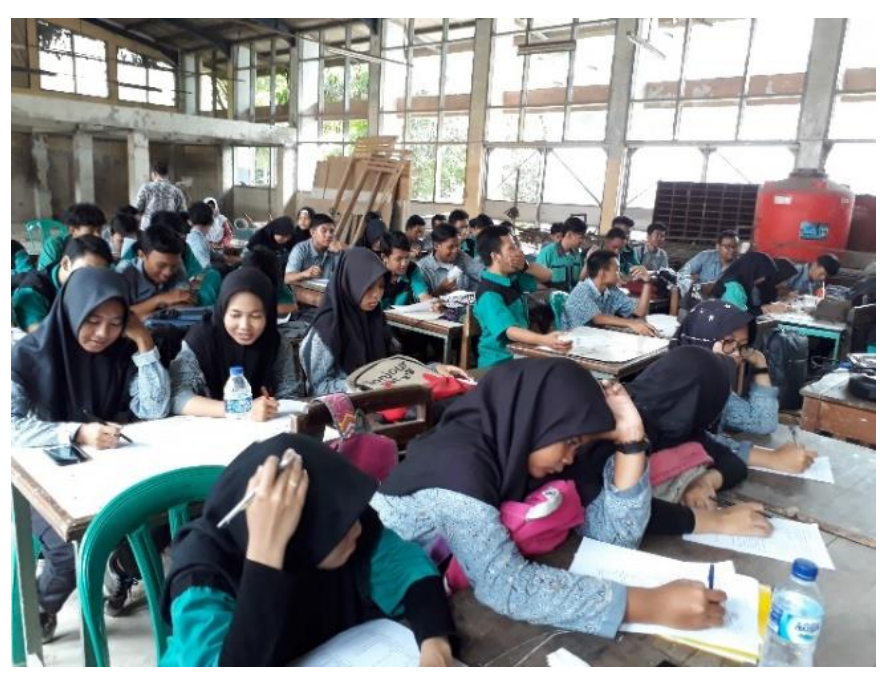

Gambar 6. Pelaksanaan Pre Test dan Post Test

Setelah dilakukan sosialisasi dan edukasi, siswa dan siswi SMKN 4 Tangerang mulai memiliki pengetahuan mengenai SNI 2052:2017 Baja Tulangan Beton, yaitu megenai proses pengolahan baja tulangan beton, jenis, bahan baku, persyaratan mutu, cara uij, syarat lulus uji, syarat penandaan, dan cara pengemasan ${ }^{[1]}$. Hal ini dapat terlihat dari hasil pre test dan post test yang dilakukan pada kegiatan sosialisasi dan edukasi yang mengalami kenaikan sehingga menunjukkan adanya peningkatan pengetahuan siswa dan siswi SMKN 4 Tangerang. Sebelum diberikan edukasi, nilai rata-rata pre test sebesar 2,5 sedangkan setelah diberikan edukasi, nilai rata-rata post test sebesar 7,0. Hasil pre test dan post test tentang pengetahuan baja tulangan beton dapat dilihat pada Tabel 1 dan Gambar 7 . 
Tabel 1. Hasil Nilai Pre Test dan Post Test

\begin{tabular}{|c|c|c|c|}
\hline \multicolumn{2}{|c|}{ HASIL NILAI PRE TEST } & \multicolumn{2}{c|}{ HASIL NILAI POST TEST } \\
\hline Nilai & $\begin{array}{c}\text { Jumlah Siswa } \\
\text { (orang) }\end{array}$ & Nilai & $\begin{array}{c}\text { Jumlah Siswa } \\
\text { (orang) }\end{array}$ \\
\hline 0 & 5 & 0 & 0 \\
\hline 1 & 13 & 1 & 0 \\
\hline 2 & 10 & 2 & 1 \\
\hline 3 & 11 & 3 & 0 \\
\hline 4 & 4 & 4 & 8 \\
\hline 5 & 2 & 5 & 4 \\
\hline 6 & 2 & 6 & 14 \\
\hline 7 & 0 & 8 & 7 \\
\hline 8 & 0 & 9 & 2 \\
\hline 9 & 2 & 10 & \multicolumn{2}{c|}{} \\
\hline 10 & 0 & 7,0
\end{tabular}

Sumber: Hasil Analisis

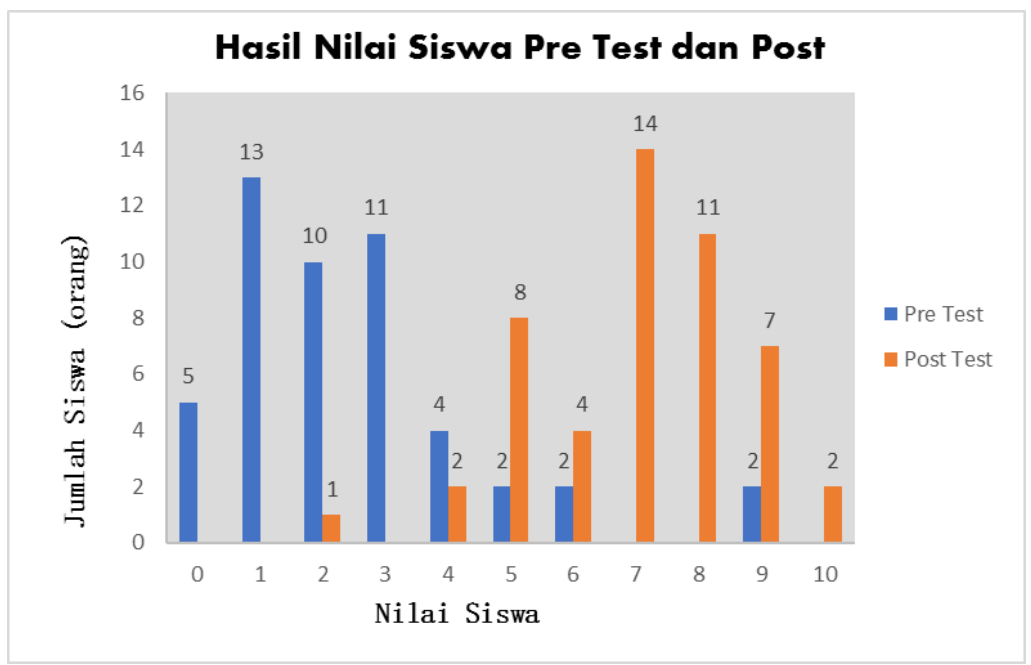

Gambar 7. Grafik Hasil Pre Test dan Post Test

Melalui kegiatan sosialisasi dan edukasi ini dapat diketahui bahwa SMKN 4 Tangerang telah memahami pentingnya pengetahuan akan baja tulangan beton yang sesuai dengan standar nasional serta pengetahuan akan keamanan konstruksi, keselamatan, dan kesehatan bagi pemakai serta menjamin kepentingan konsumen dan masyarakat.

\section{KESIMPULAN DAN SARAN}

Setelah kegiatan sosialisasi dan edukasi terlaksana, beberapa hal yang telah dicapai adalah peserta memahami akan pentingnya baja tulangan beton, memahami definisi dan istilah-istilah dalam baja tulangan beton, memahami proses pembuatan baja, serta 
memahami bahan baku, jenis, syarat mutu, cara pengambilan contoh, cara uji, syarat penandaan, syarat lulus uji, dan cara pengemasan tulangan beton yang digunakan untuk keperluan penulangan konstruksi beton sesuai SNI 2052:2017.

Saran dalam kegiatan PKM ini adalah diharapkan kegiatan serupa dapat diadakan tidak hanya di lingkungan sekitar kampus STT-PLN, mengingat pentingnya pengetahuan baja tulangan beton dalam kosntruksi bangunan. Kemudian adanya kegiatan lanjutan berupa pembahasan mengenai struktur bangunan untuk keperluan konstruksi beton dengan memperhatikan aspek keselamatan dan keamanan.

\section{UCAPAN TERIMAKASIH}

Penulis mengucapkan terima kasih kepada STT-PLN, SMKN 4 Tangerang, dan seluruh dosen Teknik Sipil terlibat yang telah memberi dukungan dalam membantu pelaksanaan kegiatan program kemitraan masyarakat. Apabila terdapat banyak kekurangan dalam artikel ini peulis memohon maaf atas kekurangan tersebut. Semoga artikel ini dapat bermanfaat bagi para pembaca.

\section{DAFTAR PUSTAKA}

[1] Badan Standarisasi Nasional, (2017), SNI 2052-2017: Baja Tulangan Beton.

[2] Gunadarma, (2008), Baja Dan Sifat-Sifatnya.

[3] https://wiryantodotblog.files.wordpress.com/2016/08/21-mislan-putra-baja-deli.pptx diakses tanggal 5 Februari 2019. 